\title{
Political Decision Making in Face-to-Face Groups: Theory, Methods, and an Empirical Application in Switzerland
}

\author{
ROBERT H. DORFF \\ North Carolina State University \\ JURG STEINER \\ University of North Carolina, Chapel Hill \\ University of Geneva
}

\begin{abstract}
This article presents a model of decision making and introduces a new theoretical variable to the literature, namely, the modes of decision making. The theoretical focus is on the face-ro-face group, and the article also develops an innovative methodology for studying this type of decision-making behavior. Variation in the decision modes is explained as a function of the strategic considerations of individual decision makers. These considerations are affected by a set of four independent variables: structure of the decision group, substance of the conflict, context of the conflict, and the decision process. The dala, drawn from observations of decision-making groups in Swizerland, are tested with discriminant analysis and a simulation. In both cases total correct classifications exceed 55 percent, indicating that there is a meaning ful structure relating variation in the decision modes to the theoretical framework.
\end{abstract}

How the political scientist should study decision-making behavior remains a perplexing and unresolved issue. The discipline has witnessed the rise (and fall?) of numerous competing approaches, ranging from the exclusively macrolevel systems approach and its now muchmaligned "black box" to the spate of economic models focusing on the individual, rational decision maker acting largely in isolation. Until fairly recently, political scientists have appeared somewhat wary of studying decision making at a level of analysis that falls somewhere in between these macro- and micro-analytic approaches, namely, at the level of the "face-to-face" group. In other disciplines, notably social psychology, a great deal of research on face-to-face groups has been conducted. Kirkpatrick (1976) points out the utility to political scientists of such a theoretical focus in a special issue of the American Behavioral Scientist which focuses on small group theory, while Golembiewski (1970) contains a collection of essays on precisely this topic. Other examples of useful research in this area include Fiorina and Plott (1978), Hinckley (1979), Sullivan (1976), and Verba (1961).

The purpose of this article is to explore the possibility of developing a general theory of political decision making in face-to-face groups. In an ear-

We would like to acknowledge the financial and institutional support of the Swiss National Science Foundation, the Institute for Research in Social Science at the University of North Carolina, Chapel Hill, and the Research Initiation Grant Program of Michigan State University. lier study (1980b), our theoretical concern was focused largely at the macro-level of whole political systems: we attempted to demonstrate that what was understood conceptually as "consociational democracy" was in reality a much more complex set of decision-making norms and behavior than heretofore assumed by the theory. In the present context we want to demonstrate the extent to which our theoretical framework can contribute to a broader understanding of a general class of political decision-making behavior in committees.

\section{Data: Background and Description}

Our data are drawn from observations of the Free Democratic party of the Berne Canton in Switzerland. The basic research method was participant observation. As is so often the case with research of this nature, access to the decisionmaking groups was largely the fortuitous result of the social scientist happening to be in the right place at the right time. As a member of the FDP, Jurg Steiner was able to secure the much-needed access not only to all the relevant committee meetings, but also to interview data, recorded minutes of meetings, and to other internal and external flows of communication in the party. During the 21 months in which he carried out his observations (January 1969-September 1970), Steiner observed the decision-making behavior in 111 committee meetings. These meetings ranged in size from the very large party conventions $(N=150)$ to the very small bureau of the executive committee (four members). Consequently, we are not dealing solely with small face-to-face decision-making 
groups, but with large, even cumbersome ones as well.

Our units of analysis are individual, openly articulated conflicts in the groups. At least two participants had to express explicit disagreement on a particular point before the disagreement could qualify as a conflict. If a conflict reappeared in a later meeting of the same committee, it was treated as a second case because under these new circumstances the actual decision-making process might very well differ from that of the first meeting. In all, we obtained data on 466 such conflicts.

\section{Dependent Variable: Modes of Decision Making}

One of the central problems confronting studies of face-to-face decision-making groups is the selection of an appropriate dependent variable. Most studies focus on the decision outcome itself, attempting to explain the group decision as a function of individual preference orderings. Predicting such outcomes generally requires that the researcher have a fairly extensive knowledge of individual preferences prior to and during the decision process. In real-world settings it is often extremely difficult, if not impossible, to obtain such information; recurrent interviewing of participants can seriously disrupt the normal course of political business in any decision-making group.

In this study we will introduce a dependent variable that has received relatively little systematic attention in the professional literature, namely, the modes of decision making. Rather than focusing our attention on the substantive outcome of a decision, we will look instead at the decision mechanism by which that outcome was achieved. The assumption is that the decision outcome will often be strongly.influenced by the decision mode. Thus the innovativeness of group decisions may depend on the mechanisms by which groups arrive at their decisions. In addition, the decision modes may have implications for a wide range of variables that are important from the perspective of normative democratic theory, such as the willingness of group members to participate in further meetings and the level of hostility and antagonism in such groups.

\section{Typology}

We have developed our typology of decision modes along three dimensions: (1) Whether or not the substance of the conflict was resolved, (2) the degree of formalization of the decision, and (3) the persistence of dissent within the group. When a conflict arises and disagreement is openly articulated, the first question one needs to ask is whether or not the substance of that conflict is re- solved in that particular meeting. Although "deciding not to decide" is obviously a decision of sorts, it is limited to the procedural matter of leaving the conflict unresolved. Since the substance of the conflict remains unresolved, the possibility exists that it will be brought up again later; it is also possible that postponement is tantamount to "killing" a proposal, much as occurs at times in the U.S. Congress when a bill is referred back to a committee. Regardless of the specific reasons for postponement or the eventual outcome of a subsequent conflict concerning the issue, we consider these unresolved conflicts as no decisions. Obviously, this term has a much narrower definition than the term nondecision originally used by Peter Bachrach and Morton S. Baratz (1962).

If the substance of a conflict is resolved by the group, it may be accomplished in a formalized or informalized manner. The possible advantages of an informal decision mechanism include the fact that it reduces the clear distinction between winners and losers, which can at times help to preserve harmonious intragroup relations, and it allows for subtle manipulation of the decisionmaking process. An informal decision occurs when one (or more) of the participants simply interprets what he/she considers to be the essence of the discussion, and then succeeds in obtaining the tacit support of the other participants for this interpretation. We have labeled this mode of decision making decision by interpretation and we can distinguish three ways in which such interpretations are made: (1) by the committee chairperson in a final summary, (2) by the secretary in the minutes, and (3) by individuals in the decision-making process who tacitly interpret the preference of the group and then direct the discussion in such a way that a decision is implicitly made. One of the central characteristics of a decision by interpretation is that, while it does resolve the substance of a conflict, it does not give any clear indication of whether the disagreement in the group persists or vanishes in the course of discussion. This decision mode also provides substantial leeway for those group leaders who are adept manipulators of the decision-making process.

A formal decision mode is one in which the participants who have expressed an opinion in the course of a discussion are required to take a visible stand on the issue when a decision is made. If dissent among group members persists, we will have a majority decision: a vote will be taken that will distinguish a winning side from a losing side. The criteria for winning may be a simple plurality, an absolute majority or a qualified majority such as two-thirds of the votes. If, however, the disagreement disappears at the end of the discussion, the resulting decision will be achieved through amicable agreement. Such an agreement may be 
Table 1. Typotogy of Decision Modes About Manifest Conflicts in Face-to-Face Groups

\begin{tabular}{|c|c|c|c|}
\hline & \multicolumn{2}{|c|}{ Resolved Conflict } & Unresolved Conflict \\
\cline { 2 - 4 } & $\begin{array}{c}\text { Formalized } \\
\text { Decision }\end{array}$ & $\begin{array}{c}\text { No Formalized } \\
\text { Decision }\end{array}$ & \\
\hline $\begin{array}{c}\text { Persistence } \\
\text { of Dissent }\end{array}$ & $\begin{array}{c}\text { Majority } \\
\text { Decision }\end{array}$ & No Decision \\
\hline $\begin{array}{c}\text { Disappearance } \\
\text { of Dissent }\end{array}$ & $\begin{array}{c}\text { Amicable } \\
\text { Agreement }\end{array}$ & & Nerion by \\
\hline
\end{tabular}

Source: Compiled by the authors.

given through an oral statement or a gesture such as a nodding of the head. The agreement may also be expressed through a unanimous vote. Obviously, amicable agreement means only that the manifest disagreement has disappeared; whether or not latent conflicts persist among the group members is not considered.

Of these four modes of decision making, three should be quite familiar from everyday usage and various treatments in the professional literature. Of course, different labels have been applied to the mechanisms but majority rule, no decision, and amicable agreement are not fundamentally new concepts. Decision by interpretation, however, is a concept that we developed while working within this theoretical context. As we have shown elsewhere (1980a), we feel that such decisions occur frequently in a variety of contexts.

\section{Theoretical Framework}

Having sketched the important characteristics of the four modes of decision making, we move now to a consideration of our theoretical framework. Obviously, our task is to explain under what conditions specific decision modes will be employed in face-to-face decision-making groups. Before we can select the independent variables that we will use in explaining this dependent behavior, however, we must specify the theoretical framework from which we will subsequently derive our explanatory variables. We begin with a set of axiomatic assumptions concerning the general behavior of politicians in face-to-face groups and build our theoretical framework deductively, ultimately arriving at a point from which we can select a set of relevant independent variables and a number of hypotheses relating these variables to variation in the modes of decision making.

In general, we assume that politicians are individual value-maximizers. Moreover, given a set of preferences or a rank-ordering of values, these individuals will seek to maximize those values that they consider to be in their best interests. In this basic sense we share the microanalytic, rationalactor focus of most economic decision-making models. However, our theoretical approach departs significantly from these economic models in our conceptualization of the range of values that politicians maximize and the degree to which these values are assumed to remain constant over time and across issues. Specifically, we assume that the range of values can be accurately identified and subsumed under four general headings: power, group solidarity, rectitude, and lime. In addition, we assume that the individual weights assigned to these values will vary from actor to actor and, for each actor, from situation to situation.' This assumption introduces a dynamic component to our theory since we assume that no single value will always be the primary goal for every politician in every decision-making situation. The research task is then to specify under what conditions certain values are likely to be more important than others, and hence how that particular value struc-

'The validity of this assumption is supported in the works of Lehner and Schülte (1976) and MacCrimmon and Messick (1976), for example. 
ture is likely to affect the selection of a decision mode. ${ }^{2}$

We have also assumed that the selection of a decision mode by a face-to-face decision-making group depends to a significant degree on the values that the members of the group try to maximize. So, for example, one might think of an individual politician who would like to see a most preferred outcome reflected in the group decision. If this politician is concerned only with winning a particular conflict (maximizing power), and if he/she believes the necessary majority support exists, he/she might press for a vote. If, on the other hand, one fears that such a vote might lead to divisive intra-group strife, one might try to "interpret" the decision; this would allow one to achieve the objective of "winning" the conflict while at the same time facilitating the preservation of group solidarity by partially concealing the identities of those members who are in the losing minority. A decision maker who feels that the necessary support for a preferred outcome is lacking might pursue a strategy of no decision in the hope that postponement would provide sufficient time to muster that additional support. If the individual preferences are relatively weak and concerns with group solidarity are strong, it seems likely that amicable agreement will be the desired strategy. If participants are tired and/or frustrated after a lengthy decision process, calling for a quick vote may be desirable if the primary goal has become finishing the business at hand rather than finding an optimal decision outcome. In other words, the selection of a particular decision mode is assumed to be the aggregate result of the strategic considerations of individual participants in the group decision-making process. These strategic considerations, moreover, will reflect the interplay of the four values included in our model.

Of course, we anticipate that most decisionmaking situations will be characterized not by the dominance of a single value but by an interplay of the four. In many cases different participants will be motivated by different values in the same decision situation. Consequently, even our relatively short list of four values presents us with a potentially staggering number of logically possible combinations. When we add the further theoretical consideration that the rank-ordering of the four values can change for each individual within each decision situation, it becomes apparent that formulating hypotheses for all of the logically possible combinations would be a nearly endless and perhaps fruitless endeavor. Rather than pursuing this particular avenue in the development of our

\footnotetext{
'A description and analysis of these values may be found in Dorff (1978).
}

theory, we try instead to decide on the basis of our independent variables which values are likely to be most important for the largest number of participants (with some additional consideration of weighting for the more powerful group members). From this information we then make probabilistic estimates of the likelihoods of occurrence for the four modes of decision making. Although we will therefore be unable to test empirically each of the posited relationships between the values and the decision modes at the micro-level, we will be able to determine whether our more aggregate predictions based on these microanalytic linkages correspond to the observed outcomes. In the end, the fit between our model's predictions and the observed outcomes should provide some measure of the overall plausibility of the micro-level theoretical reasoning that led to the predictions. The next question, then, is: what variables influence the values that political decision makers maximize and hence, the modes of decision making that a face-to-face group employs?

\section{Independent Variables and Hypotheses}

Previous research and our knowledge of the relevant literature have helped us arrive at four sets of potential explanatory variables. These sets are organized under the following headings:

1. Structure of the decision group

2. Substance of the conflict

3. Context of the conflict

\section{Decision process}

It seems wholly plausible that the values that an individual decision maker chooses to maximize will depend on the attributes of the group within which the decision process takes place. Equally plausible is the notion that these values will be affected by the kind of conflict being debated. We also expect the broader context within which a conflict takes place to have an impact on these values. Finally, since we have stressed that we expect these values to change under certain conditions once the discussion unfolds, we assume that these values will be affected by the structure of the decision process.

A wide range of variables was employed for the four sets (see Table 2). For each of the variables we formulated a detailed hypothesis relating change in the variable to changes in the values and ultimately to changes in the modes of decision making. Each of these hypotheses was formulated prior to the completion of any data analysis; hence the nature of the hypothesized predictions is entirely a priori. Rather than presenting each of the independent variables and the related hy- 
potheses, we shall illustrate our general procedure by way of a single example.

For our example we have chosen the variable, "size of the group." First, we concentrate on the way in which the four values may be influenced by the size of the decision group. Perhaps the most obvious impact can be seen for the opportunity costs of lost time. In a large group there are more potential speakers, which raises the prospect of a lengthy discussion. At the same time the typical group member has relatively few opportunities to intervene in the discussion, and much time will be spent simply listening to other members. This mostly passive role, particularly when extended over a lengthy meeting, may contribute increasingly to the feeling that time could be better invested for other purposes. Thus the incentive grows to reduce the opportunity costs represented by this loss of valuable time. In a small group, on the other hand, the discussion tends to be shorter and everyone can participate more fully. Consequently, the decision makers generally do not perceive the time spent in the decision process as a significant opportunity cost.

In addition to its effect on considerations of time, the size of a group probably influences the importance of group solidarity as an incentive as well. Solidarity is expected to be more important in small groups because the low number of participants will lead to a high number of interpersonal interactions and, according to George Homans' well-known hypothesis, frequent interactions should be a favorable condition for solidarity (Homans, 1961). Another argument, based on Olson's work, states that in a small group each actor can contribute in a more perceptible way to maintaining the group, whereas maintaining a large group depends much less clearly on the actions and inactions of individual group members (1965, p. 65). Thus in a small group the motivation of a rational actor to work for group solidarity should be much greater than in a large group.

We anticipate that considerations of power will have a greater impact in large groups than in small groups. In part, this is due to the effect of considerations of solidarity as noted in the preceding paragraph. In addition, the larger the number of people attending a meeting, the more that meeting takes on the character of a spectacle; the more the participants feel as though they are "performing" in this spectacle, the more power considerations will be involved. Winning or losing has a much more dramatic effect in a large group than in a small group, and scoring a point in the closeness and informality of a small group is much less spectacular than scoring the same point in the limelight of a large meeting.

We can find no logical reasons why the size of the group would have an influence on considera- tions of rectitude.

The causal linkage between the size of the group, the values, and the modes of decision making can now be made. The pressure for solidarity in a small group can be best met with a decision by

Table 2 Independent Variables

\section{Structure of Decision Group}

1. Size

2. Predominance of low-status participants

3. Frequency of interactions among the members -Frequency of meetings

-Number of governmental functions of the members

4. Age of the members

- Biological age

-Political age

5. Homogeneity

-By language

-By sex

-By religion

-By education

-By occupation

-By rural background

-By place of residence*

\section{Substance of Conflict}

6. Valence nature

7. Reference group

8. Innovativeness

9. Personnel versus policy conflict

10. Perceived importance of conflict -Participation rate at the meeting - Length of the discussion

\section{Context of Conflict}

11. Time distance to parliamentary elections

12. Unlikelihood of referendum

13. Pre-parliamentary versus parliamentary stage

14. Party control of government

\section{Decision Process}

15. Formality of discussion

16. Focus of discussion

-Number of agenda points in meeting

-Number of issues within the agenda point under discussion

-Number of decisions in meeting

17. Timing of the discussion

18. Certainty of information

19. Number of proposals

20. Origin of proposals

21. Structure of debate

-Distribution of opinions

-Number of speakers with clearly expressed opinion

\section{Source: Compiled by the authors.}

*The directional sign for this variable is reversed from the other homogeneity variables. In this case a high positive value indicates a heterogeneous group; a high negative value indicates a homogeneous group. 
amicable agreement. Two potential obstacles to this decision mode are not particularly salient in small groups, namely, time pressure and considerations of power. If amicable agreement cannot be achieved in a small group, the second best choice seems to be no decision or decision by interpretation, both of which would not disrupt solidarity significantly. A majority decision appears to be the least desirable choice since it may be detrimental to solidarity. In large groups, an important consideration is the time factor which can be best served with a majority decision. A majority decision also contributes to the concerns with power since it allows each participant to stand visibly by an original position. Of course, standing by one's position can result in a loss of power if that position winds up in the minority. However, since group solidarity is relatively unimportant in large groups, the majority will be largely unconcerned with what happens to the minority, so concessions will be unlikely. Amicable agreement should be quite infrequent in large groups since achieving such agreement is both timeconsuming and premised on the salience of group solidarity.

After formulating all of our hypotheses in this manner, we proceeded to the empirical analyses.

\section{Statistical Methods of Analysis}

As a response to the categorical nature of our dependent variable, we first employed discriminant analysis. The technical nature and theoretical underpinnings of this technique have been discussed elsewhere (Dorff, 1978). For the moment we shall point out that this technique is designed to find a particular linear combination of independent variables that will maximally discriminate between two or more groups of observations. ${ }^{3}$ That combination (or combinations) is then used to classify the individual observations in one of the categories of the dependent variable. The more clearly the categories are distinguished by the $p$-dimensional vector(s) comprised of the $p$ independent variables, the more successful or accurate will be the classification procedure. The vectors provide some indication of the relative strengths (contributions) of the independent variables in distinguishing among the categories, while the classification scheme indicates the extent to which the combination(s) accurately differentiate(s) among the groups. It is in this very general sense that comparisons are often drawn between

'Technically, this amounts to solving the basic characteristic equation problem:

$$
\left(W^{-1} B-\lambda I\right) d=0 \text { when } W \neq 0 .
$$

the vector of $b$ 's and the $R^{2}$ in regression analysis and the discriminant functions and the successful classification rate in discriminant analysis.

A second, major component of our analysis was a simulation in which we attempted to classify each conflict according to the decision mode most likely to be employed under the conditions specified by the independent variables. Rather than reducing the scope and precision of our predictions by choosing more than one possible outcome, we have made single-point predictions; in other words, if two decision modes are considered likely to occur but one seems more likely than the other, we have chosen the most likely decision mode as our single prediction. It should be clear, however, that this single prediction does not reflect the fact that our theory postulates a non-zero probability for the occurrence of other decision modes (although not in all cases). Making this single prediction will mean that our overall success rate wil be considerably lower than if we made more than one prediction.

\section{Empirical Tests}

Discriminant Analysis. In Tables 3 and 4 we have reproduced the results of the discriminant analysis. Three components of these results deserve special treatment: (1) the discriminant functions and the variable loadings, (2) the location of the group centroids in the reduced space, and (3) the classification table.

1. Discriminant Functions. Discriminant functions are similar to factors in a factor analysis in that the loadings of the individual variables on the function provide some indication of the relative contribution that an independent variable makes to the discrimination among the groups; simply stated, higher loadings on the discriminant function imply greater significance of those variables. The ten variables contained in Table 3 are drawn from a pool of 21 independent variables originally employed in the discriminant analysis (see Table 2).

2. Centroids of Groups in Reduced Space. These figures indicate the locations of the four group means in the reduced three-dimensional space defined by the three discriminant functions.

This reduced list of independent variables was derived from the original 21 variables through the use of a preliminary set of bivariate analyses. The criteria for selection or exclusion included both the apparent strength of the relationship and the degree to which the nature of the relationship corresponded to our original hypotheses. For a detailed discussion of each of these variables and the bivariate analyses, see Dorff (1978), Chs. 5-8. 
Table 3. Discriminant Analysis Results

\begin{tabular}{|c|c|c|c|}
\hline \multirow[b]{2}{*}{ Variable } & \multicolumn{3}{|c|}{$\begin{array}{l}\text { Standardized Discriminant } \\
\text { Function Coefficients }\end{array}$} \\
\hline & Function 1 & Function 2 & Function 3 \\
\hline \multicolumn{4}{|l|}{ Structure of Decision Group } \\
\hline $\begin{array}{l}\text { 1. Size } \\
\text { 2. Predominance of low-status participants } \\
\text { 3. Frequency of interactions among members }\end{array}$ & $\begin{array}{c}.08 \\
-.55^{*}\end{array}$ & $\begin{array}{l}.09 \\
.40^{*}\end{array}$ & $-.48^{*}$ \\
\hline $\begin{array}{l}\text {-Frequency of meetings } \\
\text {-Number of governmental functions of the members } \\
\text { 4. Homogeneity }\end{array}$ & $\begin{array}{c}.02 \\
-.66^{*}\end{array}$ & $\begin{array}{r}-.39 * \\
.54^{*}\end{array}$ & $\begin{array}{l}-.13 \\
.49 *\end{array}$ \\
\hline $\begin{array}{l}\text {-By rural background } \\
\text {-By place of residence }\end{array}$ & $\begin{array}{l}-.09 \\
-.40^{*}\end{array}$ & $\begin{array}{r}-.11 \\
.07\end{array}$ & $\begin{array}{l}.42^{*} \\
.11\end{array}$ \\
\hline \multicolumn{4}{|l|}{ Substance of Conflict } \\
\hline 5. Valence nature of conflict & $.58^{*}$ & .03 & .19 \\
\hline \multicolumn{4}{|l|}{ Context of Conflict } \\
\hline $\begin{array}{l}\text { 6. Time distance to parliamentary elections } \\
\text { 7. Unlikelihood of referendum }\end{array}$ & $\begin{array}{l}-.10 \\
-.05\end{array}$ & -.32 & $\begin{array}{r}.53^{*} \\
-.46^{*}\end{array}$ \\
\hline \multicolumn{4}{|l|}{ Decision Process } \\
\hline $\begin{array}{l}\text { 8. Formality of discussion } \\
\text { 9. Focus of discussion }\end{array}$ & .26 & $-.49 *$ & -.18 \\
\hline \multirow[t]{3}{*}{$\begin{array}{l}\text {-Number of agenda points in meeting } \\
\text { 10. Number of proposals }\end{array}$} & $\begin{array}{l}.20 \\
.09\end{array}$ & $\begin{array}{l}-.24 \\
-.19\end{array}$ & $\begin{array}{r}.43^{*} \\
-.36^{*}\end{array}$ \\
\hline & \multicolumn{3}{|c|}{ Centroids of Groups in Reduced Space } \\
\hline & Function 1 & Function 2 & Function 3 \\
\hline $\begin{array}{l}\text { Majority Decision (MD) } \\
\text { Amicable Agreement (AA) } \\
\text { No Decision (ND) } \\
\text { Decision by Interpretation (DI) }\end{array}$ & $\begin{array}{r}-.33 \\
.54 \\
-.63 \\
.29\end{array}$ & $\begin{array}{r}-1.31 \\
-.04 \\
.28 \\
.18\end{array}$ & $\begin{array}{r}-.12 \\
.60 \\
.14 \\
-.41\end{array}$ \\
\hline
\end{tabular}

Source: Developed by the authors from data in Robert H. Dorf, "Employing Simulation Analysis in Decision-Making Theory," Ph.D. Dissertation, University of North Carolina, Chapel Hill, 1978.

*Important variables are at least half as large as the absolute value of the largest coefficient.

**The directional sign for this variable is reversed from the other homogeneity variables. In this case a high positive value indicates a heterogeneous group; a high negative value indicates a homogeneous group.

The greater the relative distance between the means, the more the groups are differentiated along that dimension. When we combine the directional sign ( + or - ) for the group mean with the directional sign for the independent variables on the discriminant function, we have an indication not only of the strength or contribution of the variables but also of the direction of the impact on the likelihood of each of the four decision modes. In order to assess this impact, we must examine the three functions in order to determine which groups are being most clearly discriminated.

A glance at the centroids for function 1 reveals that it discriminates most clearly between ND $(-.63)$ and AA (.54), with a secondary discrimination between MD (-.33) and DI (.29). Table 3 reveals further that an increase in the predomi- nance of low-status actors pushes the discriminant function in a negative direction. Consequently, as more low-status participants are involved, the function takes on an increasingly negative value and ND and MD become much more likely to occur while AA and DI become less likely. In the initial formulation of our hypotheses we had anticipated just such a result: low-status participants, being less concerned with group solidarity (AA) and too inexperienced to be able to manipulate the decision-making process (DI), are likely to vote often and to postpone decisions. When we look at the discriminant function as a whole and try to characterize it according to the major variables contributing to it, we find that the function takes on its highest positive value (thus favoring AA and DI) under the following conditions: (1) group structure characterized by a predominance 
of high-status actors who have shared a place of residence (Berne) and who have not accumulated numerous governmental functions, and (2) the substance of the conflict characterized as a valence issue. The finding concerning the number of governmental functions runs counter to our expectations. We hypothesized that as the number of these functions increased, the likelihood of interaction among group members outside of this group's meetings would increase. In so doing, this would lead to greater concerns with solidarity. The other findings are in accordance with our expectations.

The second discriminant function distinguishes almost exclusively between MD $(-1.31)$ and the three other modes of decision making. In this case five variables make the most significant contribution to the discriminant function. The relative explanatory power of the second and third functions is less than the first since, much as in a factor analysis, they pick up only that information not contained in the first function. When we look once again at the entire function and attempt to characterize it according to the five variables, we find that the function takes on its highest negative value (i.e., favoring MD) when: (1) group structure is characterized by frequent meetings, a predominance of high status actors, and a low group average for governmental functions, (2) the context is one in which a referendum is certain, and (3) the decision process is formal. Under these conditions, after having "controlled" for the information contained in the first discriminant function, the results indicate that MD would be the most likely outcome.

The primary contribution of the third discriminant function is the discrimination between AA (.60) and DI (-.41), a feature that completes the discrimination process by distinguishing between the two decision modes that previously remained relatively close together in the multidimensional space defined by the independent variables. The fact that eight variables make significant contributions to this function is a further indication of the decreasing importance of the functions; in other words, the function is expectedly more diffuse. Nevertheless, we can still attempt to characterize this function generally according to these variables. Such an attempt reveals that the function would take on its highest positive value when the following conditions exist: (1) group structure characterized as a small group, dominated by low status actors, primarily homogeneous with regard to rural residence, and with a high average number of governmental functions, (2) a context consisting of impending or recently held elections and a high possibility of a referendum on the issue, and (3) a decision process that is relatively unfocused (many agenda points) with only a few proposals on the isue. In such situations it is likely that AA would be employed and unlikely that DI would result. With the notable exception of the status variable, these results bear a close correspondence to the hypotheses that we formulated prior to the analysis.

3. Classification Table. This is the most important component of the discriminant analysis. In Table 4 we have reproduced the results of the classification procedure based on the preceding discriminant functions. For each observed decision an overall score on each of the discriminant functions is calculated. The three scores for each observation are then compared in order to predict the value of the dependent variable on the basis of the observed values of the independent variables. The classification table then indicates both the predicted and actual outcome for the observations, as well as an overall measure of percent correctly classified. The elements on the main diagonal of Table 4 are the numbers and percentages of cases correctly classified for each of the four groups.

In the present context we shall focus only on the total number of cases correctly classified rather than on the individual groups. Because of missing values for 30 of our 466 decisions, 436 cases were available for classification. Of these 242 or 55.5 percent were correctly classified according to the single mode of decision making that was employed. The question now concerns the establishment of a suitable baseline or chance model against which to compare this result in order to determine how well our model fared. In other words, what rate of successful classification might we expect if we had no theoretical model, and how does our model then perform in terms of predictive capability?

The baseline that we have chosen is derived from LaPlace's Rule of Insufficient Reason, whereby one simply guesses each category the same number of times as every other category. Our primary reason for selecting this baseline is the fact that it incorporates no prior knowledge of the marginal distribution of the dependent variable, as do other possible baselines. ${ }^{3}$ Since prior probabilities were set equal (i.e., .25) in the discriminant analysis, these predictions were not

\footnotetext{
'For example, we might guess each category only as often as its observed frequency, leading to a baseline figure of 28.4 percent [(.124) $(.124)+(.206)(.206)+$ $(.305)(.305)+(.365)(.365)]$. Alternatively, we could simply guess the modal category (decision by interpreta(ion) each time and achieve a 36.5 percent successful classification rate. The use of such information concerning the marginal distribution of the dependent variable seems inappropriate for evaluating predictions made a priori, as suggested by Hildebrand et al. (1976).
} 
based on prior knowledge of the actual distribution of the decision modes. Similarly, the predictions in our simulation are a priori and not based on the marginal distribution of the four decision modes. Consequently, the expected proportion of correct predictions that we employ as our baseline is 25 percent. 6

Having selected an appropriate baseline figure, we must now devise some means of evaluating our model's performance as compared to the chance model. Such a procedure can be derived from the general model for defining a proportionate reduction in error measure (PRE) (Hildebrand et al., 1976, 1977). By modifying the PRE measures slightly, we calculate the difference between the actual percentage of correct predictions obtained from the analysis and the number of correct predictions that one would expect from chance alone, and then divide this difference by the number of correct predictions expected from chance.' This calculation then provides us with a measure of the proportional increase in accuracy attributable to our model.

Taking the 55.5 percent successful classification rate, and employing 25 percent as the appropriate baseline, our proportional increase in accuracy measure is calculated:

$$
\frac{55.5-25}{25}=\frac{30.5}{25}=1.22 \text {. }
$$

(.25) $(.124)+(.25)(.206)+(.25)(.305)+(.25)$ $(.365)=.25$ or 25 percent.

'A similar and perhaps more familiar measure is based on Goodman's and Kruskal's Lambda and is discussed in Weisberg $(1978$, p. 562). See also Hildebrand et al. (1976, pp. 519-21).
According to this measure, we are able to improve our classification by 122 percent over what we would expect from chance alone. This increase represents a substantial improvement in our ability to classify the original observations according to the mode of decision making actually employed.

A closer examination of the important variables in the three discriminant functions reveals that group structure is a key determinant of the difference among decision modes; in all three functions variables reflecting characteristics of group structure are the most numerous. But the substance and context of the conflict, as well as the decision process, also contribute to the variation in likelihood of the decision modes. This conforms to our general model of decision making discussed earlier: group structure is the first variable that enters our flow process, and hence may be considered the most important simply because it sets the stage for the actual decision making that follows; this structure is then mediated by the type of issue being considered, the context within which the conflict takes place, and the ensuing decision process. Although discriminant analysis cannot deal ade-

\begin{abstract}
"In addition to classifying the entire data set we also performed a split half-sample analysis. This standard cross-validation procedure, conducted for both the pooled and unpooled versions of the discriminant analysis, indicated that the overall classification results are perhaps somewhat overstated as a consequence of being maximized to this specific data set. However, since the pooled version results varied only between 42 percent and 63 percent, our estimate of 55.5 percent seems to be quite reasonable. For a discussion of this cross-validation procedure see Dorff (1978, pp. 139-41).
\end{abstract}

Table 4. Classification Results

\begin{tabular}{|c|c|c|c|c|c|}
\hline \multirow[b]{2}{*}{ Actual Outcome } & \multirow{2}{*}{$\begin{array}{c}\text { Total } \\
\text { No. of } \\
\text { Cases }\end{array}$} & \multicolumn{4}{|c|}{ Predicted Outcome } \\
\hline & & $\begin{array}{l}\text { Majority } \\
\text { Decision }\end{array}$ & $\begin{array}{l}\text { Amicable } \\
\text { Agreement }\end{array}$ & $\begin{array}{c}\text { No } \\
\text { Decision }\end{array}$ & $\begin{array}{c}\text { Decision by } \\
\text { Interpretation }\end{array}$ \\
\hline Majority Decision & 43 & $\begin{array}{l}30 \\
69.8 \%\end{array}$ & $\begin{array}{l}4 \\
9.3 \%\end{array}$ & $\begin{array}{l}4 \\
9.3 \%\end{array}$ & $\begin{array}{l}5 \\
11.6 \%\end{array}$ \\
\hline Amicable Agreement & 93 & $\begin{array}{l}12 \\
12.9 \%\end{array}$ & $\begin{array}{l}47 \\
50.5 \%\end{array}$ & $\begin{array}{l}16 \\
17.2 \%\end{array}$ & $\begin{array}{l}18 \\
19.4 \%\end{array}$ \\
\hline No Decision & 134 & $\begin{array}{l}16 \\
11.9 \%\end{array}$ & $\begin{array}{l}17 \\
12.7 \%\end{array}$ & $\begin{array}{l}76 \\
56.7 \%\end{array}$ & $\begin{array}{l}25 \\
18.7 \%\end{array}$ \\
\hline Decision by Interpretation & 166 & $\begin{array}{l}22 \\
13.3 \%\end{array}$ & $\begin{array}{l}28 \\
16.9 \%\end{array}$ & $\begin{array}{l}27 \\
16.3 \%\end{array}$ & $\begin{array}{l}89 \\
53.6 \%\end{array}$ \\
\hline
\end{tabular}

Correctly Classified $=55.5 \%$

Source: Developed by the authors from data in Robert H. Dorff, "Employing Simulation Analysis in Decision-Making Theory," Ph.D. Dissertation, University of North Carolina, Chapel Hill, 1978.

Note: The italicized percentages on the main diagonal represent the percent of cases correctly classified into each of the four categories. 
quately with the flow of this process, it does appear to highlight the relative temporal importance of each set of variables. In the next step we shall try to incorporate this flow process more systematically in our analysis through the use of simulation.

Simulation Analysis. In addition to discriminant analysis, we also constructed a simulation for analyzing our data. The purpose of this simulation was to create, a priori, a classification procedure that would predict the decision mode on the basis of a reduced set of independent variables drawn from our original pool of variables. The primary strength of simulation analysis lies in its ability to handle the "flow process" nature of our model. In other words, the dynamic branching effects that we believe most accurately characterize this type of decision-making process will be replicated within the context of our simulation. Once again, we can evaluate the model's performance on the basis of the total number of cases correctly classified. We remind the reader of our earlier discussion of the single-point nature of these predictions and the implications for assessing the overall accuracy of the predictive model.

On the basis of the discriminant analysis and general correspondence with our original theoretical propositions we selected seven independent variables for our simulation.' The variables and the sets from which they are drawn are as follows:

\section{Group Structure}

1. Size of the Group

2. Political Status of the Group Members

II. Substance of the Conflict

3. Position versus Valence Issues

4. Reference Group of the Conflict

III. Context of the Conflict

5. Time before Parliamentary Elections

6. Likelihood of a Referendum on the Issue

\section{Decision Process}

\section{Origin and Number of the Proposals}

For the sake of clarity we have briefly stated our hypotheses in Table 5.

\footnotetext{
'Once again the basis for reducing the number of independent variables consists of a combination of the results of empirical tests (bivariate and discriminant analyses) and the degree to which the suggested relationship corresponded logically to our original hypotheses. If, for example, a variable displayed some discriminating power but the direction was difficult to justify in terms of our theoretical framework, we chose to exclude that variable from the simulation. The selection of these
}

The first variable that enters the process is group structure. From the moment a decision group convenes, it takes on relatively fixed structural characteristics. In particular, each group will be either small, medium, or large and will consist solely or predominantly of high-status or lowstatus actors. From our theory and the individual hypotheses contained in Table 5 (Hypotheses 1 and 2), we would expect that group structure alone would not suffice for the prediction of a single decision mode. Our theory presumes that certain tendencies should be evident under specific structural conditions but that an actual outcome will remain largely indeterminate until further information becomes available. In other words, while certain structural combinations will clearly favor one or two decision modes over the others, group structure alone should rarely (if ever) be sufficient for determining a single decision mode. Therefore, our simulation would make note of the specific characteristics of the group structure but would pass directly on to the next variable (substance) rather than taking the path to the predictions.

Once the meeting is convened, the group is confronted by an agenda of issues. In each decisionmaking situation, then, the actual substance of the conflict begins to interact with the characteristics of the group structure. In our model we distinguish between conflicts dealing with actual goals (position) and conflicts dealing with means (valence). Further, we consider the group to which a conflict refers an important determinant of the way in which the decision-making process unfolds and, ultimately, of the decision mode actually employed. However, we also expect that the criterion of position-valence will be somewhat more important than the reference group, although the interaction between the two remains crucial. Our assumption follows from the argument that the position-valence nature of a conflict will be the primary characteristic of the substance; political decision makers will consider this factor first, and only secondarily will they consider the reference group to which a particular issue refers.

In general, we also assume that the combined information regarding structure and substance will not suffice for specific predictions. Our reasoning here is that the group structure and substance of a conflict, while of primary importance in determining the resulting decision mode, will not always lead in the same direction; hence some indeterminacy must remain. Moreover, most combinations of these two sets of variables will

variables is discussed in detail in Dorff (1978, pp. 285-95). 
serve only to narrow the range of possible decision modes (for example, from four to three to two) rather than to restrict that range to a single mode which we could then predict. The exception to this indeterminacy occurs for small groups comprised solely of high-status actors or solely of low-status actors.

The context of the conflict is the third factor to affect the flow of the decision-making process. The two variables that we employ are the time interval to the parliamentary elections and the likelihood of a referendum. One might argue that the time before the elections should enter the process earlier than we have stated; however, the logic of our theory indicates that concern with elections will become salient only if the particular issue being considered is somehow relevant to the upcoming elections. Concerns with electoral impact should normally become salient only after the substance of a conflict is apparent and the preliminary discussion has taken place.

The final variable concerns the decision process. Once a meeting is convened, an issue determined, and the impact of contextual variables ascertained, the actual way in which the discussion proceeds will help determine which values will change and which will remain fixed. As we have pointed out earlier, we do not assume that the values for every actor will remain invariant; in
Fow Chart of Decision-Making Process

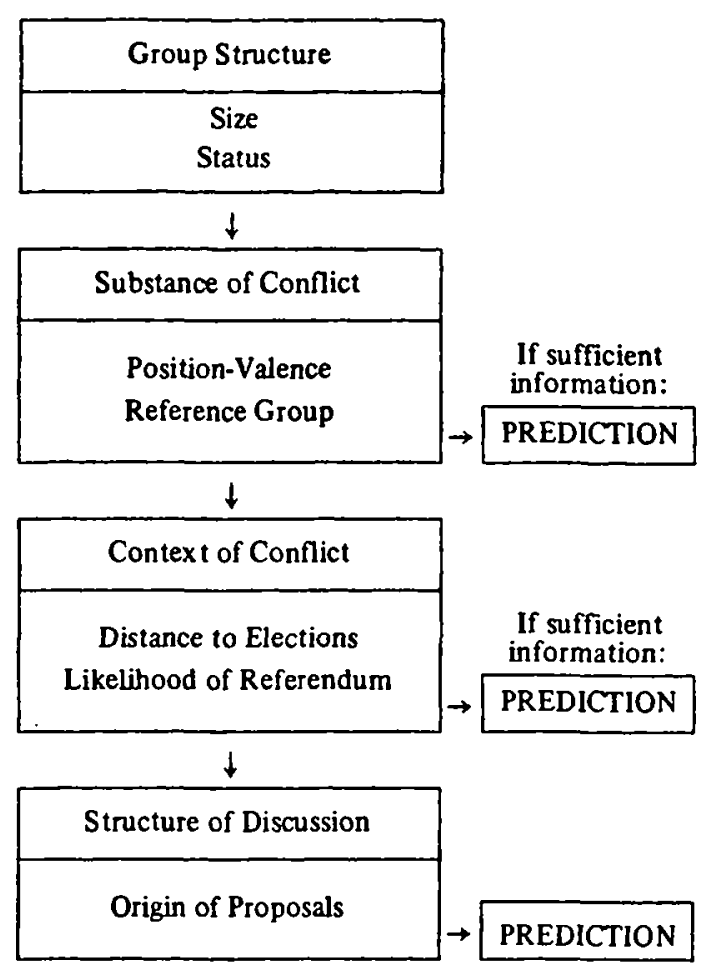

Table 5. Hypotheses for Independent Variables in Simulation

\begin{tabular}{|c|c|c|c|c|}
\hline \multirow[b]{2}{*}{ Independent Variables } & \multicolumn{4}{|c|}{... the more the probability of ... } \\
\hline & $\begin{array}{l}\text { majority } \\
\text { decision }\end{array}$ & $\begin{array}{l}\text { amicable } \\
\text { agreement }\end{array}$ & no decision & $\begin{array}{l}\text { decision by } \\
\text { interpretation }\end{array}$ \\
\hline $\begin{array}{l}\text { 1. The smaller the size of the decision } \\
\text { group... } \\
\text { 2. The larger the portion of high-status } \\
\text { actors in a decision group ... } \\
\text { 3. The more a conflict deals not only } \\
\text { with means but also with ends... } \\
\text { 4. The more a conflict refers to matters } \\
\text { of the decision group itself ... } \\
\text { 5. The closer the time distance to the } \\
\text { next parliamentary election ... } \\
\text { 6. The greater the likelihood of a } \\
\text { referendum about the issue under } \\
\text { consideration... } \\
\text { 7. The more the high-status actors in } \\
\text { the group participate in the } \\
\text { articulation of proposals... }\end{array}$ & $\begin{array}{l}\text { decreases } \\
\text { decreases } \\
\text { increases } \\
\text { is unaffected } \\
\text { increases }\end{array}$ & $\begin{array}{l}\text { increases } \\
\text { increases } \\
\text { decreases } \\
\text { increases } \\
\text { increases }\end{array}$ & $\begin{array}{l}\text { is unaffected } \\
\text { is unaffected } \\
\text { increases } \\
\text { decreases } \\
\text { decreases }\end{array}$ & $\begin{array}{l}\text { is unaffected } \\
\text { is unaffected } \\
\text { decreases } \\
\text { increases } \\
\text { decreases }\end{array}$ \\
\hline
\end{tabular}

Source: Compiled by the authors. 
fact, we make the explicit assumption that these values change from actor to actor and, for each actor, from situation to situation. We anticipate that the origin of the proposals (whether it originates with a high- or low-status participant) will be a major factor in effecting change in these values and, hence, in the decision mode that is employed.

Limitations of space simply do not allow us to provide an extensive treatment of our simulation model. Rather, we shall provide a very simple illustration of the model's performance.

For our illustrative example we have chosen one of the simplest cases because it can be described briefly. In this case only three variables are needed before we can make a prediction; the reason for this relative paucity of information lies in the fact that all three variables point to the occurrence of a single decision mode. Therefore, the combined interaction of the three variables should make this single decision mode occur quite often.

The three characteristics associated with this class of decisions are: a small group (seven or less) comprised solely of high-status actors who are discussing a valence issue. A quick glance at Table 5 reveals that our hypotheses anticipate that all three conditions strongly favor amicable agreement, while both no decision and decision by interpretation seem largely unaffecter. All three variables indicate that a majority decision is highly unlikely under these conditions. Therefore, we make the following predictions: amicable agreement is the most likely outcome and is our single-point prediction; no decision and decisions by interpretation occupy an intermediate position in which they are less likely to occur than amicable agreement but not entirely unlikely; majority de. cisions are predicted not to occur.

Our simulation, then, makes the preceding predictions and then compares them with the actual outcomes of decisions made under this particular set of circumstances. As it turns out, ten of the observed decisions were made under these conditions. Of these, six were made by amicable agreement. two by no decision, and two by decision by interpretation. For this set of decisions we have therefore achieved a successful classification rate of 60 percent. Again, however, we stress the fact that this figure does not reflect the accuracy with which we predicted the non-occurrence of majority decisions nor the seemingly correct predictions concerning the intermediate likelihoods of both no decision and decision by interpretation. While most of our predictions were considerably more difficult to make than these, and of course some were considerably less accurate, this example should illustrate the nature of the prediction process and how the results were obtained.

The entire classification process covered $\mathbf{4 3 6}$ cases. From our universe of $\mathbf{4 6 6}$ decisions we had to omit 30 cases that had missing values on some of the seven independent variables included in the simulation. For 25 of the remaining 436 decisions our prediction was indeterminate, leaving us with 411 cases for which we have actually made a single-outcome prediction. In 237 cases (57.7 percent) our predictions were correct. Employing our previous standard of evaluation we find that this figure represents a substantial improvement in our ability to classify each decision according to the actual mode of decision making that was employed. If we adopt a baseline of 25 percent, which presumes that we have no a priori knowledge of the distribution of the four modes, our 57.7 percent correct classification rate constitutes a 131 percent proportional increase in accuracy in our ability to predict the modes of decision making.

\section{Conclusion}

The results of the analysis indicate that our theoretical framework makes a significant contribution to an understanding of these group decision-making processes. The relative accuracy and compatibility of the classification results demonstrate that a substantial amount of the variation in the modes of decision making can be explained by the independent variables included in our model. But what contribution does this study make to a more general theory of decision making in face-to-face groups?

First, an examination of our independent variables would show that almost all of them are of a highly general nature. With the exception of the referendum variable, all could be applied to committee decision-making processes in a wide variety of national contexts, and the hypotheses we formulated were not simply case-specific.

Second, our dependent variable is equally broad in its range of potential applications. During the spring and summer of 1979, Robert Dorff conducted a series of 12 decision-making experiments employing graduate and undergraduate students. The groups consisted of either five or ten students. Preferences were induced monetarily and participants received a modicum of instructions - they were told only that they had to choose one of five decision outcomes on each of an indefinite series of decisions. No instructions were given concerning the decision mechanism. Yet in these experimental groups we observed a significant use of majority decision, amicable agreement, and even decision by interpretation; no decision was of course not allowed. Moreover, the experimental control for group size also resulted in clear support for our hypothesis: the larger groups voted much more often on precisely the 
same items as small groups, which were much more inclined to employ amicable agreement. These experiments clearly indicate that a theoretical focus on the modes of decision making has a broad applicability and could be useful in any political context where decisions are made in faceto-face groups. The precise refinement of our theory to deal with this more general class of behavior is the goal of our current research efforts.

Third, the contribution of our theoretical framework is not limited solely to its general applicability but includes the fact that it provides a more tractable and meaningful way of studying real-world committee decision-making behavior. Because we were able to gather almost all of our data through participant observation without grossly disturbing the decision-making groups, our methodology should open the door to more frequent and in-depth analysis of such groups. In this way, perhaps, some of the gap between the study of experimental and real-world groups might be narrowed.

In further work we have also examined some of the consequences of the modes of decision making. In particular, we have studied the effects of the decision modes on (1) the willingness of political actors to participate in meetings, (2) the level of antagonism and hatred in the group, and (3) the potential innovativeness of group decisions. Finally, since so much political decision making takes place in face-to-face groups, it is important to see what kind of group decision-making behavior we consider more or less democratic. After all, process as well as outcome is important to an understanding of political decision making. A focus on the modes of decision making should allow us to deal with these issues as well.

\section{References}

Bachrach, Peter, and Morton S. Baratz (1962). "Two Faces of Power." American Political Science Review 56: 947-52.

Dorff, Robert H. (1978). "Employing Simulation Analysis in Decision-Making Theory." Ph.D. dissertation, University of North Carolina, Chapel Hill.
Fiorina, Morris P., and Charles R. Plott (1978). "Committee Decisions Under Majority Rule: An Experimental Study." American Political Science Review 72: 575-98.

Golembiewski, Robert T., ed. (1970). The Small Group in Political Science: The Last Two Decades of Development. Athens: University of Georgia Press.

Hildebrand, David K., James D. Laing, and Howard Rosenthal (1976). "Prediction Analysis in Political Research." American Political Science Review 70: 509-35.

(1977). Prediction Analysis of CrossClassifications. New York: John Wiley.

Hinckley, Barbara (1979). "Twenty-One Variables Beyond the Size of Winning Coalitions." Journal of Politics 41: 192-212.

Homans, George C. (1961). Social Behavior: Its Elementary Forms. New York: Harcourt, Brace, Jovanovich.

Kirkpatrick, Samuel A. (1976). Introduction to Special Issue on Small Group Theory, American Behavioral Scientist 20: 5-9.

Lehner, Franz, and Hans Gerd Schütte (1976). "The Economic Theory of Politics: Suggestions for Reconsideration." In Brian Barry (ed.), Power and Political Theory: Some European Perspectives. New York: John Wiley.

MacCrimmon, Kenneth R., and David M. Messick (1976). "A Framework for Social Motives." Beha. vioral Science 21: 86-100.

Olson, Mancur (1965). The Logic of Collective Action: Public Goods and the Theory of Groups. Cambridge, Mass.: Harvard University Press.

Steiner, Jürg, and Robert H. Dorff (1980a). "Decision by Interpretation: A New Concept for an Often Overlooked Decision Mode." British Journal of Political Science 10: 1-13.

(1980b). A Theory of Political Decision Modes: Intraparty Decision Making in Switzerland. Chapel Hill: University of North Carolina Press.

Sullivan, Terry (1976). "Voter's Paradox and Logrolling: An Initial Framework for Committee Behavior on Appropriations and Ways and Means." Public Choice 25: 31-44.

Verba, Sidney (1961). Small Groups and Polirical Behavior: A Study of Leadership. Princeton, N.J.: Princeton University Press.

Weisberg, Herbert F. (1978). "Evaluating Theories of Congressional Roll-Call Voting." American Journal of Political Science 32: 554-77. 